\title{
Focus on psychiatry in Italy
}

\section{MARCO PICCINELLI, PIERLUIGI POLITI and FRANCESCO BARALE}

Italy has experienced a significant change in its mental health sector, with a radical shift from old mental institutions to new community-based psychiatric services. The Italian experience attracted international attention and, in some instances, led to similar changes occurring abroad. Recently, economic considerations are imposing additional challenges on the health care system in general, with psychiatry facing distinct and peculiar problems due to its unique organisation and objectives. This paper aims:

(a) to provide a historical overview of the changes in mental health provision in Italy over the past century;

(b) to describe the present organisation of mental health services;

(c) to show the impact of financing on the mental health sector;

(d) to acknowledge the education and training programmes in mental health;

(e) to outline research directions and activities.

\section{FROM OLD TIMES TO THE REFORM LAW}

The first comprehensive law on mental health in Italy dates back to 1904 . At that time, the mental hospital was regarded as the cornerstone of the care system, 'admitting individuals with all types of mental disorders of any cause whatsoever, when they were dangerous to themselves or the others or were prone to public scandal' (Legge n. 36, 1904). Admission to a mental hospital could be requested by anyone 'in the interest of the patient or the society' (Legge n. 36, 1904) and even by the police on the basis of a medical certificate. The police soon became the most common source of referral since most admissions took place under emergency conditions. Admissions were compulsory, might last indefinitely and implied the loss of civil and political rights. Each province was responsible for the local provision and organisation of mental health care and set up its own mental hospital, which was kept apart from the general health care system.

It was not until the 1950s and 1960s that the situation changed, thanks to the introduction of psychotropic drugs complementing other biological treatments, such as electroconvulsive therapy (ECT), and the altered social and political climate of those years, with the fight against social discrimination and inequalities, including those suffered by individuals with mental disorders. Social psychiatry offered a new paradigm and imposed a conceptual reconsideration and practical reorganisation of mental health care. Innovations were introduced, mainly across northern and central Italy, based on the recognition of patients' needs and the attempt to tailor interventions accordingly within the mental hospital; the creation of new services outside the mental hospital; the discharge of longstay patients to the community; and the prevention of new admissions to mental hospitals.

The ongoing process of deinstitutionalisation required a different service provision and organisation, and the burden and responsibility fell on local authorities in the absence of national legislation. In 1968, a new national law (Legge n. 431) was passed, integrating the former one and including:

(a) the reduction in size of mental hospitals;

(b) a ratio of at least 1 to 4 between staff members and patients, with personnel also including psychologists and social workers alongside doctors and nurses;

(c) the creation of psychiatric wards within general hospitals, bringing psychiatry into the realm of medicine for the first time in Italy;

(d) the legitimacy of voluntary admissions to mental hospitals, with patients being granted the role of active partners in the care process, with the preservation of their civil and political rights;

(e) the establishment of community-based out-patient services to provide treatment and support to patients discharged from mental hospitals.

From here, deinstitutionalisation accelerated. Cohorts of long-stay patients in mental hospitals gradually declined with an increase in voluntary admissions lasting for shorter periods. Between 1962 and 1977, beds in public mental hospitals dropped in number from 97946 to 70070 and patients from 91237 to 58445 ; on the other hand, admissions to mental hospitals increased from 72290 to 92212 and discharges from 66564 to 93546 , with a corresponding decrease in the average length of stay from 209 to 142 days. This trend was complemented by increasing admissions to private psychiatric clinics, nursing homes for the elderly and neurological wards in public and private hospitals.

In spite of these changes, it soon became apparent that standards of care remained inadequate and, therefore, a radical reorganisation of mental health care seemed to be necessary. In 1978, under the pressure of a popular referendum aimed at the abrogation of the existing law, with the consequent delegitimisation of mental hospitals, a reform law (Legge no. 180) was devised and approved by the Italian parliament over a limited time period. This law was then incorporated into a more comprehensive legislation setting up the National Health Service.

\section{THE REFORM LAW AND ITS EFFECTS}

The reform law marked a turning point in mental health care organisation both from a local and an international perspective. Specifically:

(a) new admissions to existing mental hospitals were no longer allowed, no new mental hospitals or similar facilities were to be built, and a gradual closure of existing mental hospitals had to be planned;

(b) prevention, care and rehabilitation in mental health were assigned to new community-based services, functionally integrated among themselves. These services were expected to deal with the 
full array of mental health needs of the community and no selection or 'filters' were applied in the care process. Geographically defined catchment areas related to given multidisciplinary teams were identified in order to provide patients with continuity of care on a long-term basis;

(c) compulsory admissions to psychiatric wards were regarded as exceptional, had to be time-limited and were allowed only when out-patient interventions were ineffective or refused by patients.

Unfortunately, the reform law set out some general principles and guidelines but did not provide detailed standards for service and staff provision, nor did it allocate a proper budget for setting up the new services. Each region was expected to define proper norms and methods according to the existing local situation. This led to an uneven implementation of the law and undermined the credibility of the legislation itself (which became known as Italy's 'mad law').

The number of patients staying in mental hospitals continued to decline over time. In 1994, there were 79 public mental hospitals and 18 private ones, caring for a total of 20556 patients. Patients staying in mental hospitals tended to be elderly, to suffer from severe disability, to have physical and mental comorbidity and to have been there, on average, for over 30 years. In Rome, Bacigalupi et al (1988) reported an excess mortality in females staying in a mental hospital compared with those discharged into the community, whereas no significant difference was found in males. Long-stay patients had lower mortality rates than those staying in mental hospital for less than 6 years. On the other hand, Valenti et al (1997) found that staying in a mental hospital and a length of stay between 10 and 25 years were strong predictors of mortality, relative risks being 8.1 and 4.2 , respectively.

New community-based services were set up at an accelerating rate. In 1992, there were 1369 out-patient facilities (3.88 centres per 150000 inhabitants); 341 general hospital wards with 4285 beds ( 0.76 beds/ 10000 inhabitants); 353 residential facilities with 2905 beds $(0.60$ beds $/ 10000$ inhabitants); and 325 day hospitals and day centres with 1635 beds $(0.34$ beds/ 10000 inhabitants). Residential facilities, day hospitals and day centres were unevenly distributed across Italy, with $56.5 \%$ of them located in the north and only $19.4 \%$ in the south. Overall, they were still lacking in $78.5 \%$ of local health districts.

\section{SUBSEQUENT INTEGRATIONS OF THE REFORM LAW}

Homogeneous application of the reform law on a national basis required a better definition of objectives, interventions and standards. Thus, a national plan for mental health was launched for 1994-1996, supporting: the implementation of a comprehensive network of mental health services within each local health district, with special emphasis on rehabilitation and crisis interventions; the creation of departments of mental health, providing managerial and operational coordination to the network of mental health services; a greater attention to the training of personnel in light of the complex tasks posed by working in the community; and the definitive dismantling of old mental hospitals under a general awareness that their delegitimisation was not accompanied by proper plans to discharge patients and offer them social integration in the community.

The first national plan for mental health had limited effectiveness for reasons such as the paucity of specific guidelines, insufficient monitoring of the processes under way and lack of sanctions against noncompliant health managers. Thus, a second national plan for mental health was launched for 1998-2000 in order to provide a better definition of objectives and practical suggestions on interventions. It was acknowledged that deinstitutionalisation was coming to an end, although at different rates in different geographical areas. Standards were set for residential facilities in the community in order to facilitate the discharge of patients still resident in mental hospitals and to prevent the new facilities from resembling the old-style mental hospital. The new community-based services within the framework of the department of mental health had to deal with the full array of mental health needs of the population and operate as a real alternative to the old-style mental hospitals.

In 1996, 75 public mental hospitals were still operating and caring for 11803 patients. About half of these patients were considered to be mainly suffering from psychiatric illness, while the remainder had physical disabilities or needed assistance because of old age. In 1998, 4769 patients were still resident in 39 public mental hospitals. In 1996, there were 11 private mental hospitals with 3726 patients, dropping to 10 in 1998 with 2935 patients. Only the combined effects of strict legal pressure and financial sanctions forced the definite closure of all mental hospitals nationwide, by 31 December 2000. Inevitably, in some instances only titles were changed to comply with legal requirements and the same patients remained in the same facilities, to be cared for by the same personnel.

Almost no clinical and psychosocial data were routinely collected to monitor the deinstitutionalisation process. A notable exception is the QUALYOP study, comparing the closure policies of 22 mental hospitals located in three northern regions and in Rome. The study showed that, for many patients, delay in discharge from mental hospital was more for administrative reasons than clinical considerations, including shortage of money and lack of cooperation by local health authorities. Indeed, according to staff ratings, more than two-thirds of patients showed no behavioural problems and aggressive behaviour was reported in only $19 \%$ of cases. Autonomy in daily activities was complete for $41 \%$ of the sample and satisfactory for an additional $24 \%$. Nevertheless, no change in residential conditions was planned for $89 \%$ of patients over the year following baseline assessment (Frattura \& D'Avanzo, 1998; D’Avanzo et al, 1999).

\section{THE DEPARTMENT OF MENTAL HEALTH}

At present, the department of mental health is expected to promote and coordinate mental health prevention, care and rehabilitation within a defined catchment area. It is based on a multi-disciplinary team (psychiatrists, psychologists, nurses, social workers, educators, occupational therapists, personnel with specific training in psychosocial rehabilitation and secretarial staff) and deals with the full array of mental health needs of the adult population. It also offers long-term comprehensive interventions and continuity of care. Four types of services are anticipated within the department:

(a) the community mental health centre;

(b) the general hospital in-patient ward; 
(c) semi-residential facilities (day hospital and day centre);

(d) residential facilities.

The community mental health centre is generally responsible for planning and coordinating interventions across different facilities and settings. It is open for at least 12 hours a day from Monday to Friday and half a day on Saturday. Patients have direct access and referral from primary care doctors is not required. Demands of care are evaluated by the multi-disciplinary team and patients may receive direct interventions or be referred to other mental health facilities or different types of service, where necessary. The team working at the community mental health centre arranges domiciliary visits and is involved in consultation-liaison interventions in the local area.

The general hospital in-patient wards are located in hospitals which have an accident and emergency department. They provide crisis interventions on a short-term basis and patients are then referred back to the community mental health centre for out-patient care or other types of intervention. Most admissions take place on a voluntary basis and only a minority are compulsory. Psychiatrists working in inpatient wards are usually involved in consultation-liaison programmes with medical and surgical wards located in the general hospital.

The day hospital allows complex diagnostic assessments and therapeutic interventions on short- and medium-term bases. It may be located within the general hospital (although separated from the inpatient ward) or outside the hospital and is functionally integrated with the community mental health centre.

The day centre is open for at least 8 hours a day for 6 days a week and implements programmes promoting self-care and the practical and interpersonal skills required in everyday life.

Residential facilities promote patients' psychosocial rehabilitation and integration and may offer different levels of staff supervision and types of intervention in order to meet patients' specific needs. By law, these facilities have a limited number of beds and are placed in urban areas in order to avoid social isolation and ensure intensity of care.

In May 2000, 1370 non-hospital residential facilities were operating in Italy with a total of 17138 beds. The resulting average rate of 2.98 beds per 10000 inhabitants was higher than the recommended national standard ( 2 beds per 10000 inhabitants). Marked variations were detected across regions, with a tenfold difference between those with the lowest and the highest bed rates. In each region, the number of beds in residential facilities was negatively correlated with the availability of community-based psychiatric services and positively correlated with the number of beds in private psychiatric clinics. This suggests that a comprehensive network of community-based services may limit the number of patients staying in residential facilities. About three-quarters of residential facilities had 24-hour staff supervision, provided long-term intensive care and had low patient turnover. As might be expected, the probability of discharge was lower in those facilities providing intensive supervision and with a high proportion of patients who had previously been admitted to a mental hospital. However, private facilities predicted a low patient turnover after controlling for clinical variables, suggesting that financial considerations may also play a significant part (Gruppo Nazionale PROGRES, 2001).

Despite common national guidelines, the establishment of new community-based services across Italy was slow and unevenly distributed. Initially, greater efforts were devoted to the implementation of general hospital in-patient wards and out-patient clinics, to the relative detriment of residential facilities. The increasing availability of out-patient services was not accompanied by a substantial reduction in hospital admissions and psychiatric beds. Variability in service provision has diminished over time, with a move from regional variability to a variability across different services with no strict relationship with their geographical location (Tansella et al, 1987, 1991; Bollini \& Mollica, 1989; Crepet, 1990; De Salvia \& Barbato, 1993; Fioritti et al, 1997; de Girolamo \& Cozza, 2000).

Today, almost $80 \%$ of the mental health departments in northern and central Italy have larger catchment areas than originally planned (no more than 150000 inhabitants) owing to the merger of separate health districts for financial reasons. About two-thirds of the departments are organised according to particular functional areas (i.e. in-patient, out-patient and rehabilitation activities), each with relevant personnel and coordinators. Whereas a community mental health centre is found in all the departments and a general hospital in-patient ward in around $80 \%$ of the departments, only $60 \%$ to $75 \%$ of the departments are provided with residential facilities (Commodari \& Commodari, 1999). The relative lack of these facilities in the public sector favours private clinics, which are contracted by the National Health Service to satisfy unmet needs. Although the process of accreditation by an independent agency ensures that standards of care are attained, public control remains difficult and strict economic reasons may favour patients' selection and 'speculative' forms of care.

Table 1 summarises the distribution of mental health services in Italy according to the most recent statistics.

\section{INTEGRATION OF THE DEPART MENT OF MENTAL HEALTH WITH OTHER SERVICES}

Substance misuse disorders and mental disorders in children and adolescents are treated by specialist services which are not part of the department of mental health and have separate facilities and personnel. Until recently, these services operated independently and contacts with the department of mental health were sporadic, unplanned and unstandardised. Better integration and closer collaboration between different services is now emerging as a leading principle in the mental health sector. 'Territorial Pacts for Mental Health' is a new strategy promoting the functional integration of health, social, economic and vocational resources (both public and private) available in a given catchment area. Within this framework, prevention and treatment interventions may be offered to individuals throughout their life by taking into account their specific and complex needs, their family and the local environment (Frattura, 2000).

With health and social expenses being increasingly reduced, the community itself is expected to play a crucial role through vocational and self-help organisations. In 1997, 12909 vocational organisations operated in Italy's social sector (1 for every 3500 people on average), including more than 360000 participants. About $75 \%$ of these organisations offered social support 
Table I Distribution of mental health services in Italy (modified from de Girolamo \& Cozza, 2000; with permission from Elsevier Science)

\begin{tabular}{|c|c|c|c|}
\hline Service & Number & Rate & National standard ${ }^{4}$ \\
\hline Community mental health centres & $695^{1}$ & $1.81 / 150000$ inhabitants & $1 / 150000$ inhabitants \\
\hline Out-patient facilities & $1132^{\prime}$ & $2.95 / 150000$ inhabitants & Not available \\
\hline General hospital in-patient wards & $320^{1}$ & $0.83 / 150000$ inhabitants & Not available \\
\hline General hospital in-patient beds & $4084^{\prime}$ & $0.7 / 10000$ inhabitants & $1 / 10000$ inhabitants \\
\hline Private psychiatric clinics & $65^{2}$ & $0.17 / 150000$ inhabitants & Not available \\
\hline Private psychiatric beds & $5595^{2}$ & $0.9 / 10000$ inhabitants & Not available \\
\hline University psychiatric departments & $19^{2}$ & & \\
\hline University department beds & $404^{2}$ & & \\
\hline Day hospitals & $257^{\prime}$ & $0.67 / 150000$ inhabitants & Not available \\
\hline Day hospital beds & $942^{\prime}$ & $0.1 / 10000$ inhabitants & $1 / 10000$ inhabitants \\
\hline Day centres & $481^{\prime}$ & $1.26 / 150000$ inhabitants & $1 / 150000$ inhabitants \\
\hline Non-hospital residential facilities & $1377^{3}$ & $3.43 / 150000$ inhabitants & Not available \\
\hline Non-hospital residential beds & $17343^{3}$ & $3 / 10000$ inhabitants & $\mathrm{I}-2 / 10000$ inhabitants \\
\hline Mental health staff (total) & 309781 & $0.81 / 1500$ inhabitants & I/1500 inhabitants \\
\hline Psychiatrists & $5094^{1}$ & $0.13 / 1500$ inhabitants & Not available \\
\hline Psychologists & $1785^{\prime}$ & $0.05 / 1500$ inhabitants & Not available \\
\hline Nurses & $15482^{1}$ & $0.41 / 1500$ inhabitants & Not available \\
\hline
\end{tabular}

I. Ministero della Sanità (1998).

2. Istituto Italiano di Medicina Sociale (1997).

3. Gruppo Nazionale PROGRES (200I).

4. Second national plan for mental health.

and health interventions, with mental disorders, learning disability and abnormal behaviours ranking high in their lists of priorities. Of the organisations in the mental health sector, $60 \%$ included relatives of individuals with mental disorders and about three-quarters retained close functional links with mental health services. Most organisations were located in northern and central Italy, twice the number in southern Italy. A positive correlation was found between the number of vocational organisations in a given area and the socio-economic level of the local population and availability of public interventions in favour of at-risk groups. This suggested that vocational resources tended to gather in wealthy areas at the expense of those areas most needing them (data provided by Fondazione Italiana per il Volontariato).

\section{FINANCING AND MENTAL HEALTH ORGANISATION}

In Italy, health care is provided by the National Health Service, and each citizen must be registered with a primary care doctor. Citizens have unlimited health care coverage, although they contribute through charges on drug prescriptions (with the exception of so-called essential drugs), laboratory tests or diagnostic investigations. Within the National Health Service, regions are divided into local health districts, each providing health care to the population of a defined catchment area. Citizens are not forced to receive care locally and may contact any health facility, irrespective of its geographical location.

Italy has the highest level of doctors among all Western countries (5.9 per 1000 inhabitants), with a large number being unemployed or underemployed. In comparison, the UK and Ireland have about 2 doctors per 1000 inhabitants. Contrary to other countries, in Italy doctors outnumber nurses, who are estimated to number 5.3 per 1000 inhabitants (Sasso, 2001).

Until 1992, there was no strict control on health expenditures in Italy. A national budget for health was set by the government each year and then divided among the regions. In principle, each region was expected to assign a proper budget to each local health district on the basis of given health indicators. In practice, this was not done, with local health districts having no financial autonomy and no limitations on their expenditures. Excess expenditure was covered by the government through ad hoc financial interventions.

In 1992, local health districts and hospitals were granted financial and managerial autonomy. Each local health district has a budget for health care based on the size of the local population, the number of health care facilities and other health-related indicators.

Each district uses its budget to run its own health facilities or to 'buy' interventions from other services, such as hospitals (run by distinct trusts) or private services under contract to the National Health Service, which offer specialist care. Charges for these are agreed partly with the Ministry of Health and partly with the regional health office.

In order to be chargeable, health interventions must be:

(a) produced by services meeting given legal standards, thus ensuring the quality of their output; in other words, each service has to undergo a process of so-called accreditation by a specific agency before its health interventions will be reimbursed by the National Health Service;

(b) consistent with operational criteria defining distinct categories of possible interventions (e.g. diagnostic interview, individual psychotherapy, drug administration);

(c) expressed in cost units (e.g. days of inpatient stay, number of out-patient contacts).

Although these restraints are aimed at containing health expenditures and ensuring a satisfactory quality of health interventions, there are some limitations, particularly in the area of mental health.

First, it soon became apparent that operational standards were difficult to set in psychiatry, owing to lack of agreement in the definition of diagnostic paradigms and therapeutic approaches. Therefore, accreditation of mental health services was based only on structural (i.e. number and types of facilities) and organisational criteria (i.e. availability of personnel, working hours, functional links with other services, etc.). In the absence of operational criteria, each mental health department is not required (by law, at least) to implement a comprehensive set of effective interventions. Apart from drug treatments, which are widely available, psychotherapeutic and rehabilitation interventions may be based more on the availability, training and cultural paradigms of the personnel than on evidence-based data. It follows that therapeutic interventions are subject to 
significant geographical variation and patients with mental disorders may be offered different standards of care across the country.

A second issue refers to the emphasis placed on economic considerations, with health services (which have financial autonomy) being urged to undertake more interventions in order to increase their income. This might affect the efficacy of interventions, with the danger that they might be tailored more to their economic value than to patients' needs. Moreover, interventions generating high income may receive priority, irrespective of their impact on the outcome for patients. Under these conditions, efficiency might be expected to fall, since a similar (or, in some cases, lower) efficacy of interventions is obtained at higher cost.

Finally, selection of interventions may lead to selection of patients. A service might be prone to offer mainly those interventions which are more convenient in economic terms and, thus, to select its users. This may be especially true for mental health. At present, accurate charging for mental health interventions is far from satisfactory, since psychopathology, by itself, does not accurately predict costs, with personal, social and health system variables affecting them to great extent. Therefore, some interventions may be more convenient than others, since the average level of costs is lower than the expected reimbursement. For example, hospital-based interventions retain relatively higher economic value than out-patient contacts. This consideration has encouraged a switch from community- to hospital-based interventions in spite of the cultural tradition which led to the implementation of the Italian Reform Law. A great effort is being made in Italy (and also in the international community) to model mental health costs more accurately in order to avoid distortions in mental health interventions.

\section{EDUCATION AND TRAINING IN MENTAL HEALTH}

\section{Medical students}

In 1996, there was a significant reform of educational programmes in the faculties of medicine nationwide, with psychological issues as a whole receiving greater attention and higher priority. Specifically, medical students are now expected to develop 'the ability to communicate with the patient and his/her family in a clear and sympathetic way, collaborate with other health professionals in team work and detect health problems in the community' (Coggi et al, 1996).

Students may be trained in communication skills through lessons and seminars on theoretical models and interactive patterns as well as in practical sessions that include role-play and interviews with patients under proper supervision.

Difficulties in collaboration between health professionals and possible solutions may be experienced by working in small groups with a tutor, role-play and participating in ward rounds or team meetings.

Effective detection of health problems in the community requires 'an holistic approach to health and illness by considering the patient as well as his/her physical and social environment' (Coggi et al, 1996). With this aim, the strong recommendation is for knowledge to be integrated across different disciplines and domains rather than pursuing the traditional description of distinct prototypical syndromes. Drug addiction and alcohol misuse are proposed as model examples, since a comprehensive approach to these disorders covers distinct fields, including biochemistry, histology, physiology, internal medicine, obstetrics, paediatrics, infectious diseases, psychology/psychiatry, sociology, preventive medicine, rehabilitation and medico-legal issues. A community-based education has been suggested, with medical students beinginvited to attend health services in close contact with the local community, such as primary care doctors, family planning and advice clinics, and services for substance misuse.

The stated objectives and recommendations represent a distinct advance in medical education, although they face some limitations. Out of 1000 credits required to gain a degree in medicine, 700 are assigned through formal courses and training planned by the faculty. Psychology and psychiatry are allocated 25 credits $3.6 \%$ of the total). The remaining 300 credits are designated as optional, since they are gained through seminars and practical experience chosen by each student according to their personal interests. Psychology and psychiatry may be included, although students are usually offered 'balanced' solutions, strongly recommended by the faculty. Similarly, the undergraduate residential activity preceding the final dissertation does not include psychiatry among the disciplines to be practised by medical students.

\section{Psychiatrists}

In order to become psychiatrists, medical doctors have to complete a 4-year postgraduate training in academic settings or in public mental health services under special agreement with the school of psychiatry. Specifically, each postgraduate student is expected to treat no fewer than 80 patients; to offer psychotherapy to at least 20 patients under proper supervision; to be involved in at least 10 rehabilitation programmes and 5 controlled clinical trials on psychotropics; to perform at least 20 psychiatric consultations in medical settings; to be on call on 50 occasions; to administer psychometric tests to at least 40 patients; and to gain an awareness of forensic psychiatry.

Despite these common guidelines, each school of psychiatry pursues a distinct approach and develops specific interests, which strongly influence the type of training offered to postgraduate students. Whereas biological treatments are widely used, psychotherapy is less common. Moreover, available guidelines are generic and do not, by themselves, ensure a proper training in psychotherapy. Nevertheless, all those completing the 4-year training in psychiatry are licensed as psychotherapists with no further examination. Similar considerations apply to psychiatric rehabilitation and forensic psychiatry.

\section{Psychologists}

Until recently, a university degree in psychology was granted on completion of courses extending over 5 years. A 4-year postgraduate training in various psychological specialities was then required for the practitioner to have access to the National Health Service. This system is moving towards the English model, with the first 3 years conferring a bachelor's degree in psychological science and 2 additional years being required to obtain a master's degree in various psychological specialities.

In order to become a licensed psychotherapist, a psychologist has to complete a 4-year postgraduate training in psychotherapy, in academic settings (where few positions are available) or in private institutions, provided that they are certified by a proper board. Medical doctors may also have access to these institutions (as well as to the speciality of clinical psychology) to get a licence in psychotherapy. 


\section{Nurses}

A bachelor's degree in nursing is granted on completion of a 3-year university-based course. Seminars on issues related to psychology and psychiatry cover about 105 hours (out of a total of 1500) over the 3 years. About 100 hours out of 3000 are spent in practical training in mental health, by attending general hospital in-patient wards or rehabilitation services. A master's degree in mental health may also be obtained by accumulating a given number of credits.

\section{Other mental health professionals}

University-based education is now available for social workers, educators and those practising psychosocial rehabilitation and it replaces special schools operating on a regional basis. In general, courses cover several psychosocial and psychiatric issues. For social workers, field training is carried out both at the primary care and the specialist level, including mental health services.

\section{RESEARCH IN PSYCHOLOGY AND PSYCHIATRY}

Fava \& Montanari (1998) evaluated the quality of Italian research in psychology and psychiatry and its contribution to the international scientific community during 1981-1996. The resulting picture was not entirely satisfactory. For psychiatry, Italy was in ninth position regarding the number of publications and in twelfth position in respect to overall impact; for psychology, it was in eleventh position for publications and in tenth position for overall impact. This situation also seems to apply to Italian research in other scientific fields, since Italy's impact was only higher than the worldwide average in 6 of the 93 scientific disciplines included in the database of the Institute of Scientific Information of Philadelphia.

A citation analysis performed on Italian papers published in psychiatric and psychological journals between 1981 and 1998 and included in the Science Citation Index and the Social Sciences Citation Index showed that publications on neuropsychology, psychopharmacology and biological psychiatry were most frequently cited, with papers on clinical psychology and epidemiological and social psychiatry having a far lower impact (Bignami et al, 2000).

In spite of the radical changes in mental health organisation in Italy over the past decades, research in new community-based services has been scarce and unevenly distributed, possibly owing to the limited role played by universities in most mental health departments. A survey including 48 departments distributed across Italy showed that only $56 \%$ of them made a regular report of their interventions, whereas $80 \%$ performed no evaluation of results nor had a quality assurance programme (Frisanco, 1997).

In order to overcome these limitations, the second national plan for mental health stated that each department of mental health is expected to undertake an annual project to improve the quality of interventions and establish a quality assurance unit. Moreover, between 1997 and 2001, a national mental health project was coordinated by the Italian National Institute of Health and funded by the Ministry of Health. About 100 university departments of psychiatry and mental health departments operating within the National Health Service were involved. Topics under evaluation included, among others, the prevalence and incidence of mental disorders, their natural history and associated risk and protective factors; the description of mental health services in terms of facilities, interventions, costs, etc; the evaluation of efficacy and effectiveness of interventions, with special emphasis on psychotherapy, psychosocial rehabilitation and family psychoeducation; and the development of assessment instruments to be used routinely for continuous quality improvement. Training courses on relevant issues were also arranged for mental health professionals. Unfortunately, the new guidelines set by the Italian Ministry of Health research programme and the absence of a specific commitment to mental health are threatening the continuation of this project (Morosini et al, 2001).

\section{FINAL CONSIDERATIONS}

Italy has undergone radical changes in mental health care organisation which, in many respects, led to similar changes occurring abroad, phasing out old mental hospitals and implementing new community-based mental health services. Alhough reliable national data are not available, the closure of mental hospitals did not seem to be accompanied by a substantial increase in new long-stay patients, and communitybased services represented a real alternative to the old system of care and were not merely complementary to it.

New services were implemented at different rates across the country, leading to substantial inequalities. These have reduced over time and, at present, the implementation of new services can be viewed as successful in most parts of the country. Working in the new services may prove to be a rich, professional experience, since comprehensive long-term interventions are made easily available to individuals with mental disorders in the community and are implemented by multi-disciplinary teams across different settings to ensure continuity of care.

However, the quality of care is still a matter of debate. The available evidence suggests that drug treatments are often inadequate, effective psychotherapeutic, psychoeducational and rehabilitation interventions are not easily available, and inpatient admissions tend to be too short and thus inadequate for most severe illnesses, leading to high readmission rates (Barbato et al, 1992a,b; Munizza et al, 1995; Tibaldi et al, 1997).

According to a comparison made in 2000 by the World Health Organization between the health care systems of the countries affiliated to the United Nations, Italy ranked second, preceded only by France. Democratic access to health care and quality of interventions were mainly responsible for this impressive result. On the other hand, about $70 \%$ of Italians reported dissatisfaction with health care because of insufficient coordination and efficiency along the pathways to care, and limited availability of interventions (Sasso, 2001). This situation is likely to apply to mental health as well and may be responsible for the recent submission of several proposals to change the present legislation in this area, with greater social control and more custodial interventions for individuals with mental disorders.

Finally, we offer a few words on health professionals in the public sector. In our opinion, they are experiencing increasing dissatisfaction, since priority given to economic considerations and strict administrative control limits resources and interventions (e.g. under recent financial legislation, public sector employees retiring over the next 2 years will not be replaced), affects the quality of clinical work, extends bureaucracy, discourages education as a non-profit activity, reduces creativity, weakens ideals and obscures the ethical 
principles inspiring health care. Under these circumstances, Italian psychiatry, and Italian health care in general, are going through a difficult transitional period. Expectations are high, although in the absence of strong ethical principles, ideals and creativity, it is difficult for the entire system to attain high standards of care. In Anton Chekhov's The Seagull, one of the characters states that life should not be represented as it is nor as it should be, but as it appears in dreams. We hope to retain and make use of them in the future.

\section{ACKNOWLEDGEMENTS}

We thank Dr Giovanni de Girolamo and Nelson Bacchi for providing relevant material.

\section{REFERENCES}

Bacigalupi, M., Cecere, F., Arcà, M., et al (1988) La mortalità dei ricoverati negli Ospedali Psichiatrici della Regione Lazio: primi risultati. Epidemiologia e

Prevenzione, 34, 36-43.

Barbato, A., Terzian, E., Saraceno, B., et al (1992a) Outcome of discharged psychiatric patients after short inpatient treatment: an Italian collaborative study. Social Psychiatry and Psychiatric Epidemiology, 27, 192-197.

_ , _ _ , et al (1992b) Patterns of aftercare for psychiatric patients discharged after short inpatient treatment. An Italian collaborative study. Social Psychiatry and Psychiatric Epidemiology, 27, 46-52.

Bignami, G., de Girolamo, G., Fava, G. A., et al (2000) The impact on the international literature of the scientific production of Italian researchers, in the disciplines of 'psychiatry' and 'psychology'. A bibliometric evaluation. Epidemiologia e Psichiatria Sociale, 9, II-25.

Bollini, P. \& Mollica, R. F. (1989) Surviving without the asylum. An overview of the studies on the Italian reform movement. Journal of Nervous and Mental Disease, I77, 607-615.

Coggi, G., Curtoni, S. E., Danieli, G., et al (1996) Guida all'Applicazione del Nuovo Ordinamento Didattico (GU n. 255, 30 October 1996), 75012 Medicina e Chirurgia. Ancona: II Lavoro Editoriale.

Commodari, B. \& Commodari, E. (1999) ॥ dipartimento di psichiatria alle soglie del 2000. In / Servizi
Psichiatrici nella Sanità Riformata (eds P. L. Scapicchio \& M. Trabucchi), pp. 17I-240. Bologna: II Mulino.

Crepet, P. (1990) A transition period in psychiatric care in Italy ten years after the reform. British Journal of Psychiatry, 156, 27-36.

D'Avanzo, B., Frattura, L., Barbui, C., et al (1999) The QUALYOP project. I. Monitoring the dismantlement of Italian psychiatric hosptials. Characteristics of patients scheduled for discharge. International Journal of Social Psychiatry, 45, 79-92.

de Girolamo, G. \& Cozza, M. (2000) The Italian psychiatric reform. A 20 -year perspective. International Journal of Law and Psychiatry, 23, 197-214.

De Salvia, D. \& Barbato, A. (1993) Recent trends in mental health services in Italy. An analysis of national and local data. Canadian Journal of Psychiatry, 38, 195-202.

Erlicher, A. \& Rossi, G. (eds) (1999) Manuale Accreditamento Professionale per il Dipartimento di Salute Mentale. Torino: Centro Scientifico Editore.

Fava, G. A. \& Montanari, A. (1998) National trends in behavioural sciences (198I-1996). Psychotherapy and Psychosomatics, 67, 28I-301.

Fioritti, A., Lo Russo, L. \& Melega, V. (1997) Reform said or done? The case of Emilia-Romagna within the Italian psychiatric context. American Journal of Psychiatry, I54, 94-98.

Frattura, L. (2000) Verso una nuova generazione di pratiche di governo locale per uno sviluppo equo e socialmente sostenibile. L'ennesima utopia? In II volo dell'Airone. Lavoro, Casa, Gruppi, Impresa Sociale, Patti Territoriali, Pratiche Innovative di Salute Mentale: il Progetto Horizon "Airone" (eds R. Barone, V. Bellia \& Cooperativa Sociale Narciso), pp. 160-178. Milano: Franco Angeli.

_ \& D'Avanzo, B. (1998) Monitoring the Italian psychiatric hospitals closure. The QUALYOP project. Mental Health Care, II, 334-336.

Frisanco, R. (1997) Indagine Sulla Qualità dei Servizi di Salute Mentale. Rapporto di Indagine su 48 Dipartimenti di Salute Mentale. Rome: Italian Institute of Social Medicine.

Gruppo Nazionale PROGRES (200I) Psychiatric residential facilities in Italy. Results from phase I of the PROGRES project. Epidemiologia e Psichiatria Sociale, 10 260-275

Istituto Italiano di Medicina Sociale (1997)

Rilevazione delle Strutture e dei Servizi Psichiatrici Pubblici e Privati e del Personale in Essi Operante alla data del 31.12.1996. Rome: Istituto Italiano di Medicina Sociale.

Ministero della Sanità (1998) Stato di Attuazione de Processo di Superamento degli Ospedali Psichiatrici e di Realizzazione dei Dipartimenti di Salute Mentale (Legge N.
449/1997), vol I e Il, a cura dei Dipartimenti della Prevenzione e della Programmazione. Roma: Ministero della Sanità.

Morosini, P. L., de Girolamo, G., Picardi, A., et al (eds) (200I) Progetto Nazionale Salute Mentale. Rapporto Conclusivo. (Rapporti ISTISAN 0I/27.) Rome: Istitute Superiore di Sanità.

Munizza, C., Tibaldi, G., Bollini, P., et al (1995) Prescription pattern of antidepressants in out-patient psychiatric practice. Psychological Medicine, 25, 77I-778.

_, Donna, G. \& Nieddu, S. (eds) (1999)

Finanziamento e Management del Dipartimento di Salute Mentale. Bologna: II Mulino.

Sasso, L. (200I) Nurse 'emergency' in Italy. Internationa Nursing Perspectives, I, 50-54.

Scapiccho, P. L. \& Trabucchi, M. (eds) (1999) / Servizi Psichiatrici nella Sanità Riformata. Bologna: II Mulino.

Tansella, M., De Salvia, D. \& Williams, P. (1987) The Italian psychiatric reform: some quantitative evidence. Social Psychiatry, 22, 220-224.

_, Balestrieri, M., Meneghelli, G., et al (1991) I. Trends in the provision of psychiatric care 1979-1988. Psychological Medicine (suppl. 19), 5-16.

Tibaldi, G., Munizza, C., Bollini, P., et al (1997) Utilization of neuroleptic drugs in Italian mental health services. A survey in Piedmont. Psychiatric Services, $\mathbf{4 8}$ $213-217$

Valenti, M., Necozione, S., Busellu, G., et al (1997) Mortality in psychiatric hospital patients. A cohort analysis of prognostic factors. International Journal of Epidemiology, 26, 1227-1235.

Legge n. 36 Sui Manicomi e sugli Alienata, 14 February 1904

Legge n. 180 Accertamenti e Trattamenti Sanitari Volontari e Obbligatori, 13 May 1978.

Legge n. 43/ Provvidenze per l'Assistenza Psichiatrica, 18 March 1968.

Marco Piccinelli Unità Operativa di Psichiatria I, Azienda Ospedaliera Universitaria Ospedale di Circolo e Fondazione Macchi di Varese, Presidio Ospedaliero del Verbano-sede di Cittiglio, Via Marconi 40, 21033 Cittiglio (Varese), Italy, and DSSAeP, Pavia, Italy

Pierluigi Politi, Francesco Barale DSSAeP, Pavia, Italy, and Servizio Psichiatrico di Diagnosi e Cura, Pavia, Italy 